\title{
Vellozia flavicans Mart. ex Schult. hydroalcoholic extract inhibits the neuromuscular blockade induced by Bothrops jararacussu venom
}

Natália Tribuiani ${ }^{1}$, Alexandro Mateus da Silva ${ }^{1}$, Miriéle Cristina Ferraz ${ }^{1}$, Magali Glauzer Silva', Ana Paula Guerreiro Bentes ${ }^{2}$, Talita Signoreti Graziano ${ }^{2}$, Marcio Galdino dos Santos ${ }^{3}$, José Carlos Cogo 4 , Eliana Aparecida Varanda ${ }^{5 *}$, Francisco Carlos Groppo ${ }^{2}$, Karina Cogo ${ }^{2,6}$ and Yoko Oshima-Franco ${ }^{1}$

\begin{abstract}
Background: Snakebite is a significant public health issue in tropical countries. In Brazil, some of the most common snake envenomations are from Bothrops. Bothrops bites trigger local and systemic effects including edema, pain, erythema, cyanosis, infections, and necrosis. Vellozia flavicans is a plant from the Brazilian "cerrado" (savanna) that is popularly used as an anti-inflammatory medicine. Since inflammation develops quickly after Bothrops bites, which can lead to infection, the aim of the present study was to observe possible anti-snake venom and antimicrobial activities of $V$. flavicans ( $\mathrm{V} f$ ).
\end{abstract}

Methods: The chromatographic profile of the main constituents from the Vf leaf hydroalcoholic extract was obtained by thin-layer chromatography (TLC). The anti-snake venom activity was measured by Vf's ability to neutralize the in vitro neuromuscular blockade caused by Bothrops jararacussu venom (Bjssu) in a mouse phrenic nerve-diaphragm model (PND). After a 20 min incubation, preparations of PND were added to Tyrode's solution (control); Vf $(0.2,0.5,1$, and $2 \mathrm{mg} / \mathrm{mL}) ; 40 \mu \mathrm{g} / \mathrm{mL}$ Bjssu; pre-incubation for 30 min with Bjssu and $1 \mathrm{mg} / \mathrm{mL} \mathrm{Vf}$; and a Bjssu pretreated preparation (for $10 \mathrm{~min}$ ) followed by $1 \mathrm{mg} / \mathrm{mL}$ Vf. Myographic recording was performed, and the contractile responses were recorded. The antimicrobial activity (minimum inhibitory concentration [MIC] and minimum bactericidal concentration [MBC]) was obtained for Staphylococcus aureus, Pseudomonas aeruginosa, Escherichia coli, and Enterococcus faecalis, using gentamicin and vancomycin as positive controls.

Results: TLC analysis yielded several compounds from Vf, such as flavonoids (quercetin) and phenolic acids (chlorogenic acid). Bjssu completely blocked the contractile responses of PND preparations, while Vf preserved $97 \%$ $( \pm 10 \%)$ of the contractile responses when incubated with Bjssu. In the PND pretreated with Bjssu, Vf was able to inhibit the neuromuscular blockade progress. MIC and MBC of Vf ranged from 2.5 to $5.0 \mathrm{mg} / \mathrm{mL}$ for $P$. aeruginosa and S. aureus strains, while no antimicrobial activity was observed for E. coli and E. faecalis.

Conclusions: The hydroalcoholic extract from Vf leaves was able to neutralize and decrease the in vitro neuromuscular blockade caused by Bjssu. However, it did not show significant antimicrobial activity against the tested bacteria.

Keywords: Antimicrobial, Antiophidian, Medicinal plant, Snake venom

\footnotetext{
* Correspondence: varandae@fcfar.unesp.br

${ }^{5}$ Pharmaceutical Sciences Faculty of Araraquara, São Paulo State University (UNESP), Rodovia Araraquara-Jau, Km 1, Araraquara, São Paulo CEP 14801-902, Brazil

Full list of author information is available at the end of the article
} 


\section{Background}

Envenomation from snake attacks is a significant public health problem in rural areas of tropical and subtropical countries. According to the World Health Organization, there are at least 421,000 accidents involving snakes and 20,000 deaths worldwide from snakebite each year [1].

In Brazil, the genus Bothrops is a major group of snakes that commonly cause envenomation. Snakebites from this genus, which includes those of Bothrops jararacussu, are characterized by local and systemic effects, such as inflammation at the bite site, ecchymosis, bleeding, and skin infection with abscess. Snakebites are usually associated with inoculation of bacteria present in the snake's mouth, which can lead to necrosis, gangrene, and amputation [2].

There are few reports on the in vivo neurotoxicity induced by $B$. jararacussu venom. Some reports detail unspecified signs [3-5] or describe systemic effects including blindness, blurred vision, difficulty in swallowing, and paralysis, which are reminiscent of the actions of Crotalus venom [6]. However, the in vitro irreversible neuromuscular blockade induced by $B$. jararacussu venom, which was first demonstrated by Rodrigues-Simioni et al. [7], has inspired other studies with other species of Bothrops.

Vellozia flavicans Mart. ex Schult. (Velloziaceae) is a native plant from the Brazilian "cerrado" (savanna) vegetation, popularly known as "canela-de-ema". It is an herbaceousshrub used as an anti-inflammatory and anti-rheumatic in folk medicine [8]. The Velloziaceae family contains about 270 species of tropical monocotyledonous plants, many of which are found in the Brazilian tropical scrub growing on rock outcrops [9]. Branco et al. [10] characterized the chemical constituents of $V$. graminifolia, which shares phytochemical groups already found in other Vellozia plants, such as flavonoids [11,12], diterpenoids [13-15], and triterpenoids [16,17]. Although the phytochemical elucidation is relatively advanced for this family, little is known about the pharmacological properties of specific species.

Plants used as anti-inflammatory medicines could be potentially effective for treating snakebites. This pharmacological relation has been confirmed by studies that found both anti-inflammatory and anti-venom properties from some plant extracts and their compounds $[18,19]$. Therefore, as $V$. flavicans is popularly used as anti-inflammatory medicine, it could have also some anti-venom activity. To test this hypothesis, a model using $B$. jararacussu venom is better than other venoms, such as Crotalus durissus terrificus, because the latter does not induce significant inflammation in the tissues around the snake bite [20]. B. jararacussu venom causes inflammation at the bite site and induces an irreversible neuromuscular blockade in vitro, but not in vivo [7].

The aim of the present study was to observe the ability of a hydroalcoholic extract obtained from $V$. flavicans leaves to neutralize the in vitro neuromuscular blockade caused by $B$. jararacussu venom in a mouse phrenic nerve-diaphragm model. In addition, the antimicrobial activity of the same extract was verified against Staphylococcus aureus, Pseudomonas aeruginosa, Escherichia coli, and Enterococcus faecalis strains, using gentamicin and vancomycin as positive controls. Thin-layer chromatography (TLC) was used to observe the main chemical constituents of the extract.

\section{Methods}

\section{Plant material}

The leaves of $V$. flavicans were collected at Porto Nacional, Tocantins State, Brazil, in September 2011, at S10 44' 08.3" and W048 $21^{\prime}$ '46.7". The plant was identified by the Botany Section from Biology Department of Tocantins Federal University, where a voucher specimen was deposited (HTO 8533). The $V$. flavicans leaves were dried at $37^{\circ} \mathrm{C}$ over 7 days and then powdered, ground in a mill, and macerated over 5 days in $70 \%$ ethanol. Then, the suspension was percolated (under protection against light) at $20 \mathrm{drops} / \mathrm{min}$, resulting in a $10 \%(\mathrm{w} / \mathrm{v})$ hydroalcoholic extract [21]. The extract was concentrated under reduced pressure, lyophilized, and stored at room temperature without light and humidity until the assays were performed.

\section{Thin-layer chromatography}

Aliquots of $V$. flavicans extract $(10 \% \mathrm{w} / \mathrm{v}$ solved in ethanol $70 \%$ and sonicated for $20 \mathrm{~min}$ ) were spotted (5 times) on thin-layer silica gel plates ( $0.3 \mathrm{~mm}$ thick, Merck, Germany) and compared with a collection of reference phytochemicals [22]. The solvent system consisted of ethylacetate: formic acid:acetic acid:water (100:11:11:24, w/v). Both ethyl acetate and acetic acid were provided by Chemco Ind. (Campinas, SP, Brazil), while formic acid was supplied by Synth Chemical Co. (São Paulo, SP, Brazil). The standard phytochemical groups were flavonoids (quercetin and rutin) and phenolic acids (caffeic and chlorogenic acids), suspended in $1 \%$ methanol (w/v, P. A. solution, Sigma Chemical Co., St. Louis, MO, USA). The separated spots were visualized (under UV light at $360 \mathrm{~nm}$ ) with NP/PEG as follows: $5 \%(\mathrm{v} / \mathrm{v})$ ethanolic NP (diphenylboric acid 2-aminoethyl ester, Sigma Chemical Co., St. Louis, MO, USA) followed by $5 \%(\mathrm{v} / \mathrm{v})$ ethanolic PEG 4000 (polyethylene glycol 4000, Synth Chemical Co., São Paulo, SP, Brazil). The retention factors (Rf) of the extract spots were compared with the Rf of standards.

\section{Antiophidian activity}

\section{V. flavicans hydroalcoholic extract solubilization}

The lyophilized extract was solubilized in $30 \mu \mathrm{L}$ dimethyl sulfoxide (DMSO; Sigma) and added to Tyrode's solution $(5 \mathrm{~mL})$ before addition to the bath containing the biological preparation (see below). This DMSO concentration 
did not cause changes in the basal response of the neuromuscular preparation [23].

\section{Venom}

Crude venoms were collected from male and female adult $B$. jararacussu specimens (Bjssu, DL50 mouse, e.v. $=$ $5.18 \mathrm{mg} / \mathrm{kg}$ ), in a glass receptacle covered with plastic paraffin film to avoid saliva contamination. The snake specimens are kept in the Serpentário do Centro de Estudos da Natureza - CEN at the University of Vale do Paraiba (UNIVAP, São José dos Campos, SP, Brazil) [24]. After collection, the venom was immediately placed in an ice bath, lyophilized, and kept in a refrigerator at $4{ }^{\circ} \mathrm{C}$. This process was certified by Professor Dr José Carlos Cogo from UNIVAP.

\section{Animals}

Male Swiss white mice (26-32 g) were provided by Animais de Laboratorio (Anilab, Paulinia, Brazil) and housed at $25 \pm 3^{\circ} \mathrm{C}$ on a $12 \mathrm{~h}$ light/dark cycle, with food and water ad libitum. This study was approved by the institutional Commission for Ethics in the Use of Animals (CEUA) at the Federal University of São Carlos (UFSCAR) under protocol number 063/2012. All the experiments were performed following the guidelines of the Brazilian Society of Laboratory Animal Science (SBCAL).

\section{Mouse phrenic nerve-diaphragm muscle (PND) preparation}

The phrenic nerve-diaphragm [25] was obtained from mice anesthetized with halothane and killed by exsanguination. The diaphragm was removed and mounted under a tension of $5 \mathrm{~g} / \mathrm{cm}$ in a $5 \mathrm{~mL}$ organ bath containing aerated Tyrode's solution (control). This solution was composed of the following constituents (in $\mathrm{mM}$ ): $\mathrm{NaCl} 137, \mathrm{KCl} 2.7, \mathrm{CaCl}_{2} 1.8, \mathrm{MgCl}_{2}$ 0.49, $\mathrm{NaH}_{2} \mathrm{PO}_{4}$ $0.42, \mathrm{NaHCO}_{3} 11.9$, and glucose 11.1.

After stabilization with $95 \% \mathrm{O}_{2} / 5 \% \mathrm{CO}_{2}(\mathrm{v} / \mathrm{v})$, the $\mathrm{pH}$ of the solution was 7.0. Preparations were indirectly stimulated with supramaximal stimuli $(4 \times$ threshold, $0.06 \mathrm{~Hz}$, $0.2 \mathrm{~ms}$ ) delivered by bipolar electrodes from a stimulator (model ESF-15D, Ribeirão Preto, SP, Brazil) to the nerve. Isometric twitch tension was recorded with a force displacement transducer (cat. 7003, Ugo Basile, Italy) coupled to a 2-Channel Recorder Gemini physiograph device (cat. 7070, Ugo Basile) via a Basic Preamplifier (cat. 7080, Ugo Basile). The PND myographic recording was performed according to Ferraz et al. [26]. PND was allowed to stabilize for at least 20 min before addition of the following treatments: 1) Tyrode's solution (control, $\mathrm{n}=6)$; 2) lyophilized $V$. flavicans extract $(0.2,0.5,1$, and $2 \mathrm{mg} / \mathrm{mL}, \mathrm{n}=6) ; 3) 40 \mu \mathrm{g} / \mathrm{mL}$ Bjssu venom $(\mathrm{n}=6)$; 4) pre-incubation for $30 \mathrm{~min}$ of $40 \mu \mathrm{g} / \mathrm{mL}$ Bjssu venom and $1 \mathrm{mg} / \mathrm{mL} V$. flavicans extract $(\mathrm{n}=6)$, and $40 \mu \mathrm{g} / \mathrm{mL}$ Bjssu venom pretreated preparation $(10 \mathrm{~min})$ followed by $1 \mathrm{mg} / \mathrm{mL} V$. flavicans extract $(\mathrm{n}=6)$. The venom concentration was based on a dose previously described in an irreversible in vitro neuromuscular blockade assay [27].

\section{Antimicrobial activity \\ Bacterial strains and culture conditions}

The following bacterial strains were purchased from American Type Culture Collection (ATCC): Escherichia coli ATCC 25922, E. coli ATCC 10536, Enterococcus faecalis ATCC 29212, Pseudomonas aeruginosa ATCC 25619, P. aeruginosa ATCC 27853, Staphylococcus aureus ATCC 6538, S. aureus ATCC 14458, S. aureus ATCC 29213, methicillin-resistant $S$. aureus (MRSA) ATCC 33591, and methicillin/oxacillin resistant S. aureus (MRSA/ORSA) ATCC 43300. The cultures were stored at $-80^{\circ} \mathrm{C}$ in Tryptic soy broth (TSB; Difco Laboratories, Detroit, MI, USA) containing 40\% (v/v) glycerol and were routinely cultured in Tryptic soy agar (TSA; Difco Laboratories) under aerobic conditions at $37^{\circ} \mathrm{C}$.

\section{Determination of minimum inhibitory (MIC) and bactericidal (MBC) concentrations}

MIC and MBC values were determined by using the broth microdilution method according to the guidelines from the Clinical and Laboratory Standards Institute (CLSI) protocol M07-A9. Briefly, four to five colonies were harvested from pure cultures growing on TSA and were used to prepare a bacterial inoculum. Colonies were transferred into tubes containing $5 \mathrm{~mL}$ of TSB and cultured at $37^{\circ} \mathrm{C}$ until reaching turbidity equivalent to a $0.5 \mathrm{McFarland}$ standard (approximately $1.5 \times 10^{8} \mathrm{CFU} / \mathrm{mL}$ ).

V. flavicans stock solutions in 50\% ethanol (Merck, Darmstadt, Germany) were diluted (2-fold serial dilutions) in $100 \mu \mathrm{L}$ Mueller Hinton Broth (MHB, Difco Laboratories) in 96-well polystyrene microtiter plates at concentrations ranging from $0.004 \mathrm{mg} / \mathrm{mL}$ to $10 \mathrm{mg} /$ $\mathrm{mL}$.

The bacterial inoculum $(100 \mu \mathrm{L})$ was then added into each well, allowing a final concentration of $5 \times 10^{5} \mathrm{CFU} /$ $\mathrm{mL}$. Plates were incubated under aerobic conditions at $37^{\circ} \mathrm{C}$ for $18 \mathrm{~h}$ and visually inspected for turbidity after incubation. MIC was recorded as the lowest extract concentration that caused no turbidity. Solvent controls were assayed with the treatments to verify their possible antibacterial activity. Results were also compared with vancomycin, gentamicin (positive controls), and ethanol (negative control).

For MBC determination, $10 \mu \mathrm{L}$ from each well with no visible growth were plated on TSA and incubated at $37^{\circ} \mathrm{C}$ for $24 \mathrm{~h}$. MBC was considered as the lowest extract concentration that completely inhibited (100\%) the bacterial growth. Both MIC and $\mathrm{MBC}$ values $(\mathrm{mg} / \mathrm{mL}$ ) were averaged from two different experiments performed in replicate. 


\section{Statistical analysis}

Results are shown as the mean \pm SEM. Number of experiments $(\mathrm{n})$ is indicated in the legend of the figure. Student's $t$-test was used to compare all data and the significance level was set at $5 \%$.

\section{Results and discussion}

One of the criteria for selecting plants for pharmacological studies is their traditional use in folk medicine (ethnopharmacology). Selection is also based on chemical composition, especially considering certain compounds with well-known pharmacological activity [28,29]. In the present study both criteria were considered, since $V$. flavicans is traditionally used as an anti-inflammatory and antirheumatic. In addition, its chemical composition has been studied. Velloziaceae mainly contain flavonoids (phenolic compounds), diterpenes, and triterpenoids as the main secondary metabolites. Terpenoid is a term used to indicate that the substances have a common biosynthetic origin, the isoprene molecule. Flavonols are related to natural resistance factors and have some biological effects including antimicrobial and cardiovascular activities [30]. Terpenoids have other functions including growth-regulating properties, communication, and defense against insects [22].

After collection, botanical identification, stabilization, grinding, and extraction, the plant extract was qualitatively analyzed by TLC [31] to obtain a chromatographic fingerprint. TLC provides evidence of the plant's chemical composition. Figure 1 shows the TLC profile of $V$. flavicans hydroalcoholic extract. Spots 2 and 6 indicate phenolic compounds (observe the highlighted area, Rf values were $0.99,0.89,0.80,0.74,0.70,0.66,0.60,0.49$, 0.23 , and 0.13 ) including flavonols (yellow to orange fluorescence) and phenolic acids (blue fluorescence). A mixture of commercial phytochemicals (chlorogenic acid + rutin + quercetin + caffeic acid) is visualized in spot 1 , chlorogenic acid in 3 , rutin in 4, quercetin in 5, and caffeic acid in 7 . Among the many compounds, note the presence of chlorogenic acid (Rf 0.60) and quercetin (Rf 0.99) in $V$. flavicans extract, representing phenolic acids and flavonols, respectively. All of these phytochemicals were previously reported in Velloziaceae [10-17].

Chlorogenic and caffeic acids may act as antidotes against snake venoms by binding to proteins through hydrophobic interactions and hydrogen bonds [32]. Quercetin is as a potent inhibitor of lipoxygenase, which explains its anti-inflammatory properties. Quercetin has a phenolic hydroxyl group on carbon 5, a pyronic carbonyl in close proximity, and coplanarity [33].

Even using other solvent systems, terpenoids were not found when compared with their representative $\beta$ sitosterol, the most abundant of the phytosteroids. Thus, the TLC profile, acting as a plant quality control, allowed the characterization of $V$. flavicans extract and comparison with literature data. However, the pharmacological activity is mainly attributed to flavonols.

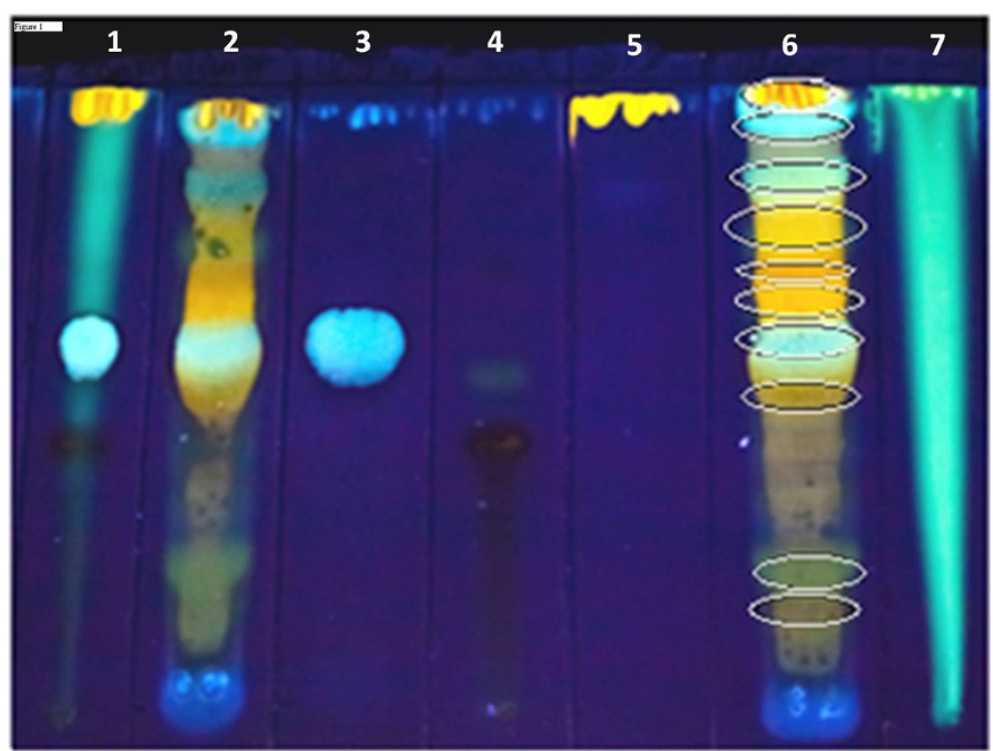

Figure 1 Thin Layer Chromatography performed by using ethyl acetate:formic acid:acetic acid:water (100:11:11:24) as solvents. Developer: NP/PEG. Phytochemical standards (inside circles): 1 - mixture of commercial phytochemicals (chlorogenic acid, rutin, quercetin caffeic acid); 2 - V. flavicans extract; 3 - chlorogenic acid $(R f=0.60) ; 4$ - rutin $(R f=0.48) ; 5$ - quercetin $(R f=0.99) ; 6$ - V. flavicans extract, showing $R f$ values of $0.99,0.89,0.80,0.74,0.70,0.66,0.60,0.49,0.23$ and $0.13 ; 7$ - caffeic acid ( $\mathrm{Rf}=$ dragged spot). $V$. flavicans extract spots are suggestive of several flavonoids (yellow/orange fluorescence) and phenolics constituents (blue fluorescence), including quercetin and chlorogenic acid, respectively. $\mathrm{Rf}=$ retention factor. 


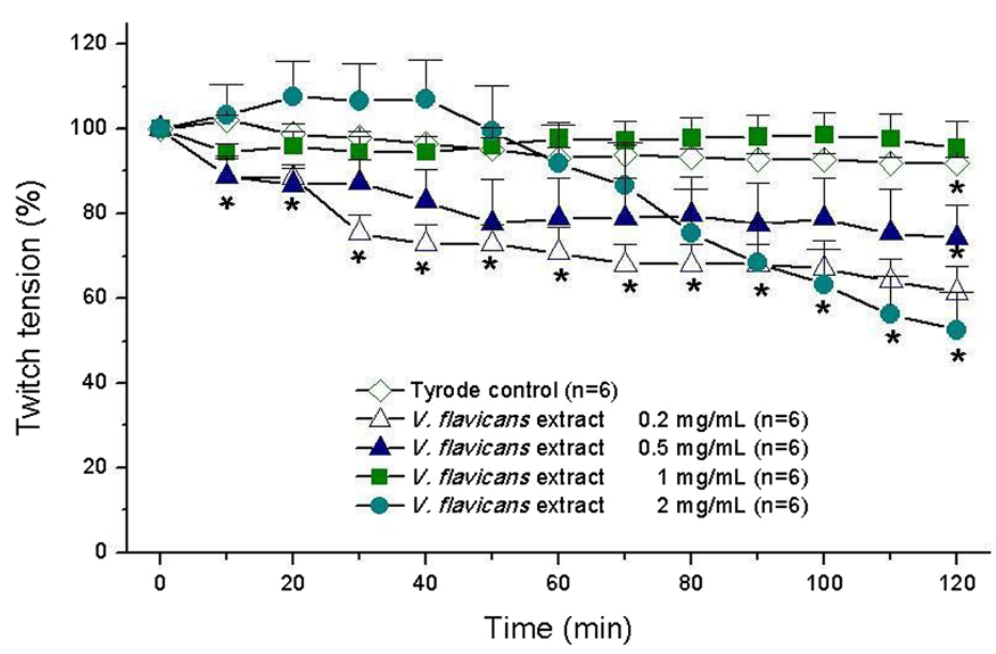

Figure 2 Mouse phrenic nerve-diaphragm preparations (indirect stimuli). Concentration-response curve of $V$. flavicans extract. Each point represents mean \pm SEM. ${ }^{*}=$ statistically significant differences $(p<0.05)$ in comparison with Tyrode control.

Mors et al. [33] proposed a correlation between the ability of plants and their chemical components to neutralize snake venoms, and their anti-inflammatory and antihepatotoxic properties. In the present study, $B$. jararacussu venom was chosen to test if a plant with anti-inflammatory properties also has antiophidian potential, because $B$. jararacussu venom causes inflammation at the bite site [34] and causes an irreversible neuromuscular blockade in vitro $[7,35,36]$.

The clinical effects of $B$. jararacussu venom are well described by Milani-Júnior et al. [37] and are similar to those of other Bothrops species. Although the mechanism of cytokine production induced by Bothrops venoms is not completely understood [38], the compounds leading to inflammation are well established. Therefore, since the anti-inflammatory properties are already attributed to $V$. flavicans [8], we decided to test the ability of this plant extract in neutralize the envenomation caused by $B$. jararacussu venom in a well-controlled and previously validated experimental design.

The World Health Organization has included snakebite envenoming as a neglected disease [39]. Few efforts have been carried out to change this, even considering the existing serum therapy. As observed in the present

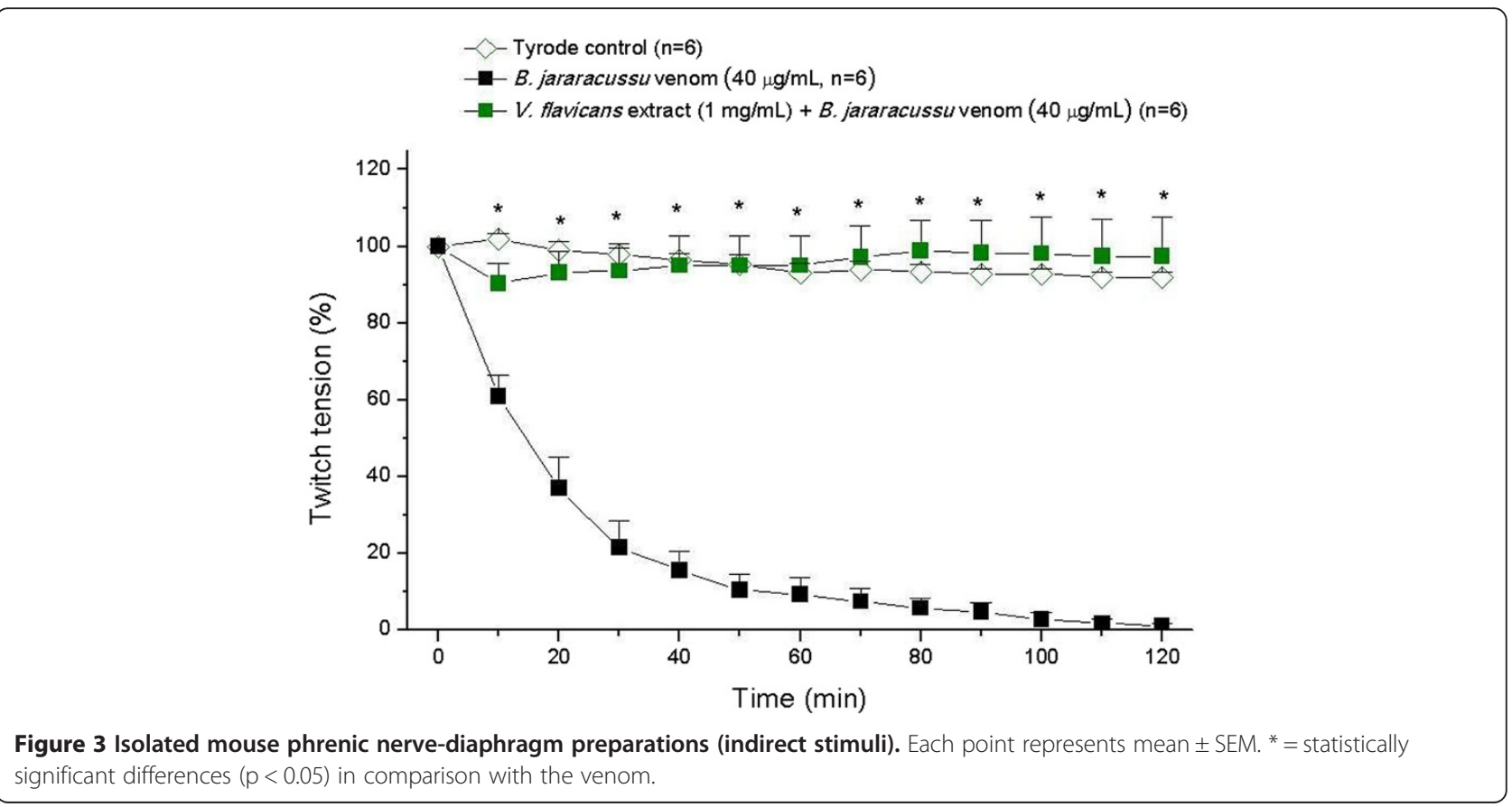




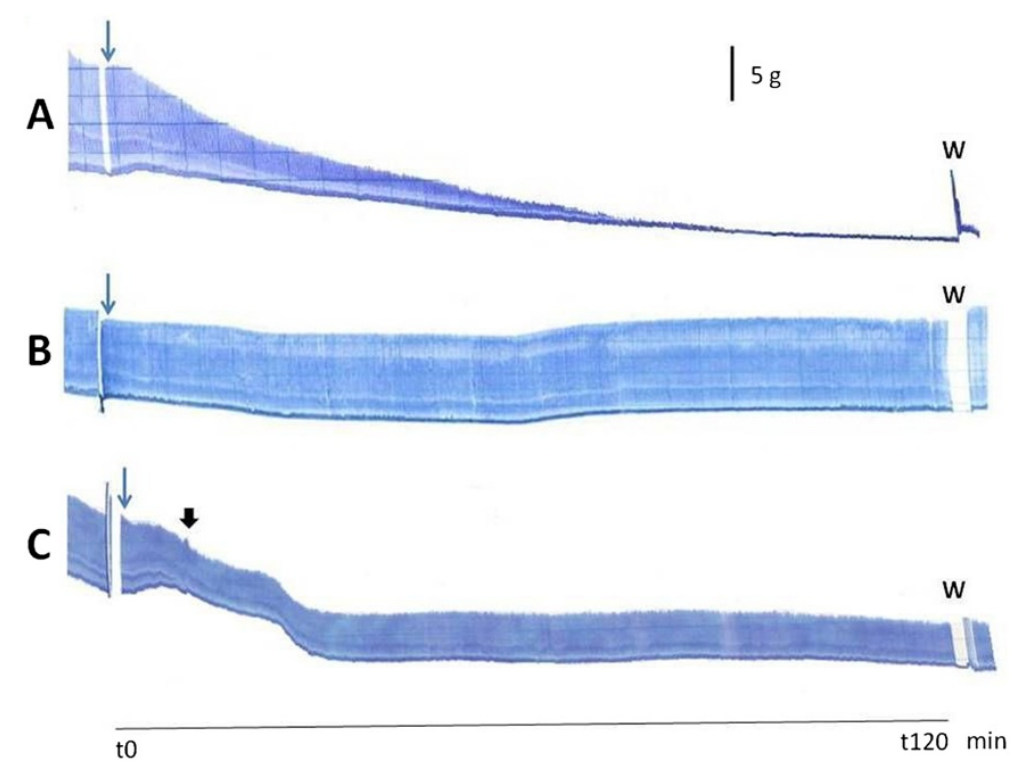

Figure 4 Representative recordings of the responses to: A, B. jararacussu venom $(40 \mu \mathrm{g} / \mathrm{mL})$ showing its characteristic irreversible neuromuscular blockade (even after washing of preparation); B, pre-incubation of $40 \mu \mathrm{g} / \mathrm{mL}$ venom and $1 \mathrm{mg} / \mathrm{mL}$ extract during $30 \mathrm{~min}$ before addition into the bath; C, Extract addition $(1 \mathrm{mg} / \mathrm{mL}$, at $10 \mathrm{~min}$, black arrow) in venom-pretreated preparation $(40 \mu \mathrm{g} / \mathrm{mL})$. Blue arrows: start of experiment (zero time). Black arrow: extract addition. $\mathrm{W}=$ washing. Vertical bar = tension.

study and some other studies, plants could be an alternative or a complementary therapy to serum treatment.

Figure 2 shows the dose-response curve (in $\mathrm{mg} / \mathrm{mL}$ ) of $V$. flavicans hydroalcoholic extract. Concentrations of $0.2 \mathrm{mg} / \mathrm{mL}(\mathrm{p}<0.05) ; 0.5 \mathrm{mg} / \mathrm{mL}(\mathrm{p}<0.05)$ and $2 \mathrm{mg} / \mathrm{mL}$ $(\mathrm{p}<0.05)$, but not $1 \mathrm{mg} / \mathrm{mL}(\mathrm{p}>0.05)$, showed significantly less twitch tension than Tyrode's control solution, indicating that these concentrations were able to interfere with the normal contraction of PND. A better result was obtained with $1 \mathrm{mg} / \mathrm{mL} V$. flavicans extract, since this concentration did not change the basal response of neuromuscular preparation. Curiously, the low concentrations $(0.2$ and $0.5 \mathrm{mg} / \mathrm{mL})$ caused a decrease in the baseline (Tyrode's solution). This result suggests a parallel regulation on skeletal muscle excitability by an unclear mechanism, since other endogenous signaling pathways are capable to compensate the cholinergic control of movement. Glutamate, for example, was recently suggested as a co-transmitter of acetylcholine in motoneurons of mammalian neuromuscular junction $[40,41]$.

Figure 3 shows the pharmacological profile of preincubated $(30 \mathrm{~min})$ venom $(40 \mu \mathrm{g} / \mathrm{mL})$ plus $V$. flavicans extract $(1 \mathrm{mg} / \mathrm{mL})$ compared with the venom alone and Tyrode's solution. The extract was able to completely abolish the decreased twitch tension caused by $B$. jararacussu venom at all times. At the end of experiment (120 min), the preparation with $V$. flavicans extract was $97 \%( \pm 10 \%)$ responsive, indicating extract efficacy.

Effectiveness of mixing a plant extract or an isolated phytochemical with a venom to abolish the venom toxic effects is not guaranteed. Success depends on the venom and plant constituents. The main constituents of $V$. flavicans very closely reproduce the results obtained with the hydroalcoholic extract of Casearia sylvestris Sw. [42] or Casearia gossypiosperma Briq. [43], which are rich in flavonoids and polyphenols. However, the results were not similar with those observed for Dipteryx alata, which is rich in triterpenoids [26,44]; Mikania laevigata, which is rich in coumarin [45]; Plathymenia reticulata Benth., which is rich in tannins [46]; or Camellia sinensis, which is rich in catechins [36]. Nevertheless, except for tannins

Table 1 Minimum inhibitory (MIC) and bactericidal (MBC) concentrations (in $\mathrm{mg} / \mathrm{mL}$ ) for $V$. flavicans extract against E. coli, E. faecalis, P. aeruginosa and S. aureus strains

\begin{tabular}{llcc}
\hline \multicolumn{1}{c}{ Bacterial strains } & \multicolumn{1}{c}{ V. flavicans } & Vancomycin & Gentamicin \\
\cline { 2 - 4 } & MIC and MBC (mg/mL) \\
\hline E. coli ATTC 25922 & NF & NF & 0.0008 \\
E. coli ATTC 10536 & NF & 0.0015 & 0.0004 \\
E. faecalis ATTC 29212 & 2.5 & NF & 0.0125 \\
P. aeruginosa ATTC 25619 & 2.5 & NF & 0.0002 \\
P. aeruginosa ATTC 27853 & 2.5 & 0.0008 & 0.0004 \\
S. aureus ATTC 6538 & 2.5 & 0.0008 & 0.0008 \\
S. aureus ATTC 14458 & 2.5 & 0.0008 & 0.0004 \\
S. aureus ATTC 29213 & 2.5 & 0.0008 & 0.0004 \\
S. aureus ATTC 33591 & 5.0 & 0.0008 & 0.0015 \\
S. aureus ATTC 43300 & NF \\
\hline
\end{tabular}

$\mathrm{NF}$ - no MIC or MBC were found considering the concentrations tested. 
and tannic acid, which act by a clearly visible precipitation [45], most of the mechanisms of action of other phytochemicals remain unclear.

Figure 4 shows the representative myographic register of $B$. jararacussu venom (A, $40 \mu \mathrm{g} / \mathrm{mL}$ ) exhibiting the characteristic irreversible muscle paralysis. When venom $(40 \mu \mathrm{g} / \mathrm{mL})+V$. flavicans extract $(1 \mathrm{mg} / \mathrm{mL})$ are preincubated together for $30 \mathrm{~min}$ before addition into the bath, the toxic effect of the venom was not expressed (B). This result shows the total protection given by the plant extract against the venom, probably by a mechanism that excludes protein precipitation, as seen in tannins and tannic acid [45]. Even in preparations pretreated with B. jararacussu $(40 \mu \mathrm{g} / \mathrm{mL})$ for $10 \mathrm{~min}$, which showed contracture and $40 \%$ of visible paralysis, the addition of $1 \mathrm{mg} / \mathrm{mL} V$. flavicans extract into the bath was able to delay the paralysis progression, in a non-preincubated model $(\mathrm{C})$. The mechanism of the in vitro, but not the in vivo, neuromuscular paralysis caused by $B$. jararacussu venom was recently demonstrated [36]. There is a direct relationship between the cell damage level and the percentage of twitch tension response [43].

The antimicrobial activities (MIC and MBC) of $V$. flavicans extract against E. coli, E. faecalis, P. aeruginosa, and $S$. aureus strains values are shown in Table 1 . All susceptible bacterial species were inhibited or killed by vancomycin and/or gentamicin, in accordance to the recommendations of CLSI. Ethanol (extract solvent) did not interfere with bacterial growth in the concentrations tested.

To assess the antimicrobial activity of a plant extract, strict endpoint criteria for $\mathrm{MIC}, \mathrm{IC}_{50}$ and/or $\mathrm{IC}_{90}$ must be considered. Generally an extract can be considered effective if it shows $\mathrm{IC}_{50}$ lower than $100 \mu \mathrm{g} / \mathrm{mL}$ [47]. The MIC values found in the present study were up to 50 times higher than the concentration considered as the maximum concentration acceptable for $\mathrm{IC}_{50}$. Therefore, $V$. flavicans extract does not possess relevant antibacterial activity, considering the high values of MIC and MBC for $P$. aeruginosa and $S$. aureus strains (2.5$5.0 \mathrm{mg} / \mathrm{ml}$ ) and the absence of inhibition of E. coli and E. faecalis strains.

Some specific plants extracts and metabolites can be effective against microorganisms and snake envenomation. Andrographis paniculata demonstrated activity against different pathogenic microorganisms [48] and it has anti-venom activity against Naja naja venom [49]. Vitis vinifera can effectively inhibit toxic effects, such as edema, hemorrhage, myonecrosis, and coagulation of human plasma induced by Echis carinatus venom [50]. $V$. vinifera can also inhibit the growth of $S$. aureus, $E$. coli, and Bacillus cereus [51]. A plant extract showing both anti-venom and antimicrobial activities would be very useful since it could be used to prevent or to treat local/systemic infection caused by snakebite [2]. Although
$V$. flavicans extract did not show good antimicrobial activity and a more appropriate experimental inflammation model was not used [34], the extract showed potential for treating Bothrops snake envenomation.

\section{Conclusions}

In conclusion, the $V$. flavicans hydroalcoholic extract showed promising results against the in vitro neuromuscular blockade-induced by $B$. jararacussu venom at the nerve-muscle apparatus. The extract reduced the characteristic cell damage induced by the venom and avoided cell damage progression.

\section{Abbreviations}

ATCC: American Type Culture Collection; B. jararacussu: Bjssu, Bothrops jararacussu; CLSI: Clinical and Laboratory Standards Institute; CFU: Colony forming units; DMSO: Dimethyl sulfoxide; D. alata: Dipteryx alata; E. faecalis: Enterococcus faecalis; E. coli: Escherichia coli; MRSA: Methicillinresistant S. aureus; MBC: Minimum bactericidal concentration; MIC: Minimum inhibitory concentration; MHB: Mueller Hinton Broth; ORSA: Oxacillin resistant S. aureus; PEG: Polyethylene glycol; PND: Phrenic nerve diaphragm;

P. aeruginosa: Pseudomonas aeruginosa; Rf: Retention factor; TLC: Thin Layer Chromatography; TSA: Tryptic soy agar; TSB: Tryptic soy broth; V. flavicans:

Vf, Vellozia flavicans; S. aureus: Staphylococcus aureus.

\section{Competing interests}

The authors declare that they have no competing interests.

\section{Authors' contributions}

The students NT, AMS and MCF were responsible for the pharmacological methodology under YOF advisory. MGS was responsible for plant quality control and chromatography. The students APGB and TSG carried out the antimicrobial assays under KC advisory. MGS was responsible for collection of plant samples obtained in Tocantins. JCC was responsible by venom certification. EAV collaborated during the manuscript writing. FCG was responsible for manuscript criticism and English language use and correction. All authors have read and approved the final manuscript.

\section{Acknowledgements}

This work was supported by São Paulo Research Foundation (FAPESP 2004/ 09705-8, 2007/53883-6, 2008/52643-4, 2008/11005-5, and 2012/08271-0).

\section{Author details}

${ }^{1}$ Pharmaceutical Sciences post-graduation program, University of Sorocaba (UNISO), Rodovia Raposo Tavares km 92.5, Sorocaba, SP CEP 18023-000, Brazil. ${ }^{2}$ Piracicaba Dental School - University of Campinas (UNICAMP), Av. Limeira 901, Piracicaba, SP CEP 13414-903, Brazil. Environmental Sciences post-graduation program, PGCiamb, Tocantins Federal University (UFT), Av NS 15 ALC NO 14, 109 Norte, Porto Nacional, Tocantins CEP 77001-090, Brazil. ${ }^{4}$ Serpentárium of the Vale do Paraíba University (CEN - UNIVAP), Av Shishima Hifumi 2911, São José dos Campos, SP CEP 12244-000, Brazil.

${ }^{5}$ Pharmaceutical Sciences Faculty of Araraquara, São Paulo State University (UNESP), Rodovia Araraquara-Jau, Km 1, Araraquara, São Paulo CEP 14801-902, Brazil. 'Dentistry Department, de Santo Amaro University (UNISA), R. Prof. Eneas de Siqueira Neto 340, Santo Amaro, SP CEP 04829-300, Brazil.

Received: 8 May 2013 Accepted: 4 February 2014

Published: 8 February 2014

\section{References}

1. $\mathrm{WHO}$ - World Health Organization: Neglected tropical diseases: Snakebite http://www.who.int/bloodproducts/animal_sera/Rabies.pdf?ua=1.

2. Brasil. Ministério da Saúde: Textos Básicos de Saúde (Cadernos de Atenção Básica; $n$. 22). Health surveillance:zoonoses; 2009.

3. Teixeira R: Forma grave do acidente por ofídios da sub-família Crotalinae. An Acad Med Bahia 1979, 2:109-135. 
4. Vellard JA: Serpentes venenosas. In Terapêutica Clínica. Edited by Cardini C, Beretervide JJ. Buenos Aires: Libreria y Editorial 'El Ateneo; 1945:265-273

5. Alves E: Medicina de Urgência. Rio de Janeiro: Livraria Atheneu; 1956:1052-1055.

6. Brazil V: Do envenenamento ophidico e seu tratamento. Colletanea dos trabalhos Instituto Butantan; 1901:31-55.

7. Rodrigues-Simioni L, Borgese N, Ceccarelli B: The effects of Bothrops jararacussu venom and its components on frog nerve-muscle preparation. Neuroscience 1983, 10:475-489.

8. Souza CD, Felfili JM: The utilization of medicinal plants in the region of Alto Paraíso of Goiás, GO, Brazil. Acta Bot Bras 2006, 20:133-142.

9. Stannard BL: Flora of the Pico das Almas: Chapada da Diamantina - Bahia, Brazil. Great Britain: Whitstable Litho Ltd; 1995:43-78.

10. Branco A, Pinto AC, Braz Filho R: Chemical constituents from Vellozia graminifolia (Velloziaceae). An Acad Bras Cienc 2004, 76:505-518.

11. Harborne JB, Williams CA, Greenham J, Eagles J: Variations in the lipophilic and vacuola flavonoids of the genus Vellozia. Phytochemistry 1994 $35: 1475-1480$

12. Williams CA, Harborne JB, Greenham J, Eagles J: Differences in flavonoids patterns between genera within the Velloziaceae. Phytochemistry 1994, 36:931-940.

13. Pinto AC, Scofield TCV, Braz-Filho R: Two new diterpenes with a rosane skeleton from Velloziaceae. Tetrahedron Lett 1983, 24:5043-5046.

14. Pinto AC, Queiroz PPS, Garcez W: Diterpenes from Vellozia bicolor. J Braz Chem Soc 1991, 2:25-30.

15. Pinto AC, Rezende CM, Antunes OAC, Correia CRD: Three isomeric diterpenes from Vellozia flavicans. Phytochemistry 1996, 42:767-769.

16. Peixoto $E M$, Pinchin $R$, Pinto AC: Constituintes químicos de Vellozia piresiana. Ciênc Cult 1979, 32:125-127.

17. Barnes RA, Pereira AL, Scofield TCV, Braz-Filho R, Pinto AC: A new triterpene from Vellozia compacta. Chem Pharm Bull 1984, 32:3674-3677.

18. Dharmappa KK, Kumar RV, Nataraju A, Mohamed R, Shivaprasad HV Vishwanath BS: Anti-inflammatory activity of oleanolic acid by inhibition of secretory phospholipase A2. Planta Med 2009, 75:211-215.

19. Magalhães A, Santos GB, Verdam MC, Fraporti L, Malheiro A, Lima ES, Dos-Santos MC: Inhibition of the inflammatory and coagulant action of Bothrops atrox venom by the plant species Marsypianthes chamaedrys. J Ethnopharmacol 2011, 134:82-88.

20. Sampaio SC, Sousa-e-Silva MCC, Borelli P, Curi R, Cury Y: Crotalus durissus terrificus snake venom regulates macrophage metabolism and function. J Leukoc Biol 2001, 70:551-558.

21. Portuguese Pharmacopoeia Committee: Portuguese Pharmacopoeia. Lisboa: Infarmed Editors, Portugal; 2002.

22. Harborne JB: Phytochemical Methods: A Guide to Modern Techniques of Plants Analysis. London: Chapman \& Hall; 1998

23. Cintra Francischinelli M, Silva MG, Andréo Filho N, Cintra ACO, Leite GB, Cruz Höfling MADA, Rodrigues Simioni L, Oshima Franco Y: Effects of commonly used solubilizing agents on a model nerve-muscle synapse. Lat Am J Pharm 2008, 27:721-726.

24. Siles Villaroel M, Rolim Rosa R, Zelante F, Furlanetto RS: Padronização da avaliação da potência de antivenenos botrópicos, em camundongos. Mem Inst Butantan 1978/1979, 42/43:325-336.

25. Bülbring $\mathrm{E}$ : Observation on the isolated phrenic nerve diaphragm preparation of the rat. Br J Pharmacol 1946, 1:38-61.

26. Ferraz MC, Parrilha LAC, Moraes MSD, Amaral Filho J, Cogo JC, Dos Santos MG, Franco LM, Groppo FC, Puebla P, San Feliciano A, Oshima Franco Y: The effect of lupane triterpenoids (Dipteryx alata Vogel) in the in vitro neuromuscular blockade and myotoxicity of two snake venoms. Curr Org Chem 2012, 16:2717-2723.

27. Puebla P, Oshima-Franco Y, Franco LM, Santos MG, Silva RV, Rubem-Mauro L, Feliciano AS: Chemical constituents of the bark of Dipteryx alata Vogel, an active species against Bothrops jararacussu venom. Molecules 2010, 15:8193-8204

28. Gottlieb O, Kaplan MA: Das plantas medicinais aos fármacos naturais. Cienc Hoje 1993, 15:51-54.

29. Souza Brito ARM: How to study the pharmacology of medicinal plants in underdeveloped countries. J Ethnopharmacol 1996, 54:131-138.

30. Martini ND, Katerere DR, Eloff JN: Biological activity of five antibacterial flavonoids from Combretum erythrophyllum (Combretaceae). J Ethnopharmacol 2004, 93:207-212.

31. Rates SMK: Plants as source of drugs. Toxicon 2001, 39:603-613.
32. Soares AM, Ticli FK, Marcussi S, Lourenço MV, Januário AH, Sampaio SV, Giglio JR, Lomonte B, Pereira OS: Medicinal plants with inhibitory properties against snake venoms. Curr Med Chem 2005, 12:2625-2641.

33. Mors WB, Do Nascimento MC, Pereira BMR, Pereira NA: Plant natural products active against snake bite - the molecular approach. Phytochemistry 2000, 55:627-642.

34. Barbosa AM, Villaverde AB, Guimarães Souza L, Ribeiro W, Cogo JC, Zamuner SR: Effect of low-level laser therapy in the inflammatory response induced by Bothrops jararacussu snake venom. Toxicon 2008, 1(51):1236-1244.

35. Oshima-Franco Y, Hyslop S, Cintra AC, Giglio JR, da Cruz-Höfling MA, Rodrigues-Simioni L: Neutralizing capacity of commercial bothropic antivenom against Bothrops jararacussu venom and bothropstoxin-I. Muscle Nerve 2000, 23:1832-1839.

36. Oshima Franco Y, Rosa LJR, Silva GAA, Amaral Filho J, Silva MG, Lopes PS, Cogo JC, Cintra ACO, Da Cruz Höfling MA: Antibothropic action of Camellia sinensis extract against the neuromuscular blockade by Bothrops jararacussu snake venom and its mais toxin, bothropstoxin-I. In Pharmacology. Edited by Gallelli L. Croatia: Intech; 2012:469-489.

37. Milani Júnior R, Jorge MT, de Campos FP, Martins FP, Bousso A, Cardoso JL, Ribeiro LA, Fan HW, França FO, Sano-Martins IS, Cardoso D, Ide Fernandez C, Fernandes JC, Aldred VL, Sandoval MP, Puorto G, Theakston RD, Warrell DA: Snake bites by the jararacuçu (Bothrops jararacussu): clinic pathological studies of 29 proven cases in São Paulo State. Brazil. QJM 1997, 90:323-334.

38. Petricevich VL, Teixeira CFP, Tambourghi DV, Gutiérrez JM: Increments in serum cytokine and nitric oxide levels in mice injected with Bothrops asper and Bothrops jararaca snake venom. Toxicon 2000, 38:1253-1266.

39. WHO - World Health Organization: Rabies and envenomings: a neglected public health issue. 2007. Available from: http://www.who.int/bloodproducts/ animal_sera/Rabies.pdf.

40. Malomouzh Al, Mukhtarov MR, Nikolsky EE, Vyskocil F, Lieberman EM, Urazaev AK: Glutamate regulation of non-quantal release of acetylcholine in the rat neuromuscular junction. J Neurochem 2003, 85:206-213.

41. Rubem Mauro L, Rocha DS Jr, Barcelos CC, Varca GH, Andréo Filho N, Barberato Filho S, Oshima Franco Y, Vila MMDC: Phenobarbital pharmacological findings on the nerve-muscle basis. Lat Am J Pharm 2009, 28:211-218.

42. Cintra-Francischinelli M, Silva MG, Andréo-Filho N, Gerenutti M, Cintra ACO, Giglio JR, Leite GB, Cruz-Höfling MA, Rodrigues-Simioni L, Oshima-Franco Y: Antibothropic action of Casearia sylvestris Sw. (Flacourtiaceae) extracts. Phytother Res 2008, 22:784-790

43. Camargo TM, Nazato VS, Silva MG, Cogo JC, Groppo FC, Oshima-Franco Y: Bothrops jararacussu venom-induced neuromuscular blockade inhibited by Casearia gossypiosperma Briquet hydroalcoholic extract. J Venom Anim Toxins ind Trop Dis 2010, 16:432-441.

44. Nazato VS, Rubem Mauro L, Vieira NAG, Rocha Junior D, Dos S, Silva MG, Lopes PS, Dal Belo CA, Cogo JC, Dos Santos MG, Da Cruz Höfling MA, Oshima Franco Y: In vitro antiophidian properties of Dipteryx alata Vogel bark extracts. Molecules 2010, 15:5956-5970.

45. Melo RF, Farrapo NM, Rocha Junior DS, Silva MG, Cogo JC, Dal Belo CA, Rodrigues Simioni L, Groppo FC, Oshima Franco Y: Antiophidian mechanisms of medicinal plants. In Flavonoids: Biosynthesis, Biological Effects and Dietary Sources. Edited by Keller RB. New York: Nova Science Publishers; 2009:249-262.

46. Farrapo NM, Silva GAA, Costa KN, Silva MG, Cogo JC, Dal Belo CA, Dos Santos MG, Groppo FC, Oshima Franco Y: Inhibition of Bothrops jararacussu venom activities by Plathymenia reticulata Benth extracts. J Venom Res 2011, 2:52-58.

47. Cos P, Vlietinc AJ, Berghe DV, Maes L: Anti-infective potential of natural products: how to develop a stronger in vitro 'proof-of-concept' J Ethnopharmacol 2006, 103:290-302.

48. Mishra US, Mishra A, Kumari R, Murthy PN, Naik BS: Antibacterial activity of ethanol extract of Andrographis paniculata. Indian J Pharm Sci 2009, 71:436-438

49. Premendran SJ, Salwe KJ, Pathak S, Brahmane R, Manimekalai K: Anti-cobra venom activity of plant Andrographis paniculata and its comparison with polyvalent anti-snake venom. J Nat Sci Biol Med 2011, 2:198-204.

50. Mahadeswaraswamy YH, Nagaraju S, Girish KS, Kemparaju K: Local tissue destruction and procoagulation properties of Echis carinatus venom: 
inhibition by Vitis vinifera seed methanol extract. Phytother Res 2008 22:963-969

51. Oliveira DA, Salvador AA, Smânia A Jr, Smânia EF, Maraschin M, Ferreira SR: Antimicrobial activity and composition profile of grape (Vitis vinifera) pomace extracts obtained by supercritical fluids. J Biotechnol 2013, 164:423-432.

doi:10.1186/1472-6882-14-48

Cite this article as: Tribuiani et al: Vellozia flavicans Mart. ex Schult. hydroalcoholic extract inhibits the neuromuscular blockade induced by Bothrops jararacussu venom. BMC Complementary and Alternative Medicine 2014 14:48

\section{Submit your next manuscript to BioMed Central and take full advantage of:}

- Convenient online submission

- Thorough peer review

- No space constraints or color figure charges

- Immediate publication on acceptance

- Inclusion in PubMed, CAS, Scopus and Google Scholar

- Research which is freely available for redistribution 